\title{
IN SILICO DRUG DESIGN AND MOLECULAR DOCKING STUDIES OF NOVEL COUMARIN DERIVATIVES AS ANTICANCER AGENTS
}

\author{
SIMPI MEHTA, SEEMA R PATHAK* \\ Department of Chemistry, Amity University, Gurgoan - 122 050, Haryana, India. Email: srpathak@ggn.amity.edu
}

Received: 28 December 2016, Revised and Accepted: 28 January 2017

\begin{abstract}
Objective: Cancer is the major worldwide problem. It arises due to uncontrolled growth of cells. In the present study, a series of novel coumarin derivatives were designed and computationally optimized to investigate the interaction between designed ligands and 10 protein data bank (pdb) files of five selected proteins. The objective here was to analyze in silico anticancerous activity of designed ligands to reduce cost and time for getting the novel anticancerous drug with minimum side effects.
\end{abstract}

Methods: Docking studies were performed to find out the maximum interaction between designed ligands and selected five proteins using Schrodinger software Maestro. Capecitabine has been used as reference compound. Structures of selected proteins were downloaded from protein data bank.

Results: All the designed ligands showed mild to excellent binding with proteins. Most of the ligands exhibited better interaction compared to reference compound capecitabine with all pdb files. Some of the designed ligands among (1-7) showed excellent docking score with all pdb files $(2 \mathrm{v} 5 \mathrm{z}, 2 \mathrm{v} 60,2 \mathrm{v} 61)$ of amine oxidase.

Conclusion: All the designed ligands were docked with 10 pdb files of five different proteins, and it was found that out of seven designed ligand, ligand 4 showed the best binding (docking score -10.139) with pdb $2 \mathrm{v} 5 \mathrm{z}$ of protein amine oxidase. Docked ligand cavity of ligand 4 showed important hydrophobic/non-polar residues such as Ile199, Ile316, Trp119, Phe168, Ile198, Cys172, Tyr188, Tyr398, Tyr435, Phe343, Tyr60, Leu328, Leu171, and showed pi-pi interaction with Tyr326. Further wet laboratory studies are continued in our laboratory to confirm and find out efficiency and activity of target compounds.

Keywords: Docking, Monoamine oxidase, Coumarin derivatives, Anticancerous activity, Binding energy, Ramachandran plot, Hydrophobic residue.

(C) 2017 The Authors. Published by Innovare Academic Sciences Pvt Ltd. This is an open access article under the CC BY license (http://creativecommons. org/licenses/by/4. 0/) DOI: http://dx.doi.org/10.22159/ajpcr.2017.v10i4.16826

\section{INTRODUCTION}

In spite of the development of many cancer drugs in recent years [1], cancer is considered the major threat for human health [2]. Coumarin is one of the most widespread scaffolds in medicinal chemistry, and its derivatives are reported to possess anticancerous property [3] along with other biological activities [4,5].

Monoamine oxidases (MAOs) are flavin adenine dinucleotides containing an enzyme which are tightly bound to the outer membranes of mitochondria through a cysteine residue that catalyzes the degradation of monoamine neurotransmitters and dietary amines by oxidative deamination, which produces a by-product, hydrogen peroxide, a major source of reactive oxygen species [6]. There was significant correlation found between increased levels of MAOA expression and high Gleason grade or poorly differentiated human prostate tumors [7]. Coumarin derivatives have been recognized as potential MAO inhibitors [8]. It is a cytosolic reductase and is upregulated in many human cancers compared to adjacent normal tissues [9]. Dicoumarol and series of 4-hydroxycoumarin derivatives have been reported to inhibit overexpressed NAD $(\mathrm{P}) \mathrm{H}$ dehydrogenase (quinone) 1 (NQO1) in many cancer cells [10]. Epidermal growth factor receptor (EGFR), a member of ERBb family of tyrosine kinase of Rtk and, is associated with pathogenesis and development of different types of cancers $[11,12]$.

Coumarin derivatives like Daphnetin have been identified as EGFRPTK inhibitors [13]. The enzyme cytochrome P450 2A6 (CYP2A6) is a key factor in genesis and treatment of breast cancer cells [14] and lung cancer [15]. P450 2A6 activate procarcinogens and also play a major role in the inactivation and activation of anticancer drugs [16]. Binding of P450 2A6 with coumarin and methoxsalen are also reported in literature [17]. Protein kinase C (PKC) has proved an interactable target in cancer therapeutics [18]. PKC a prototypical class of enzyme which gives signals the molecules that are linked with multiple cellular processes of cancer. Furo-coumarinsulfonamides acts as PKC inhibitors particularly for cancer tumors [19]. Anticancerous drugs in the market are reported to have cytotoxic properties, coumarin compounds having antioxidant and cytostatic properties so it can minimize side effects caused due to existing drugs, radiotherapy and surgery [20]. Neo-tanshinlactone a coumarin-containing compound is reported to have better selectivity and potency than tamoxifen [21]. These valid information from literature showing the involvement of selected proteins in genesis of cancer and their binding affinity with coumarin derivatives prompted authors to design novel coumarin derivatives.

Molecular docking study is a well-established technique to determine the interaction of two molecules. This technique evolves the best orientation of ligand and protein forming a complex with minimum energy [22,23]. Typically, it is used in the process of developing new drugs and identifies proteins responsible for the appearance or progression of disease in the body. The designed novel coumarin-based ligands, 1-7 have been subjected for studying binding interactions with five receptors. In the present study, novel coumarin derivatives were analyzed for their in silico anticancer activity against 10 protein data bank (pdb) files of five proteins, namely, amine oxidase, NQ01, EGFR, CYP2A6, and protein kinase and their docking scores were compared with the reference compound capecitabine by computational docking protocol. 


\section{METHODS}

\section{Ligand preparation}

Three-dimensional (3D) structures of all atoms in molecules can be generated using LigPrep. While preparing ligands for molecular docking two-dimensional (2D) structures are converted into 3D structures for generating variations, correction, verification, and optimization of the structures. While binding with ligands receptors adopts more than one conformation. Ligands of novel coumarin derivatives were designed by substituting $3^{\text {rd }}, 5^{\text {th }}, 6^{\text {th }}, 7^{\text {th }}$, and $8^{\text {th }}$ position of coumarin nucleus. $5^{\text {th }}, 6^{\text {th }}$, $7^{\text {th }}$, and $8^{\text {th }}$ positions were substituted with hydroxyl, acetoxy, iodine, and $-\mathrm{CF}_{3}$ group, respectively. The third position of coumarin nucleus was substituted with phenyl group.

A general structure of designed ligands (Prototype 1) and reference compound is mentioned in Fig. 1, substituents of designed ligands with their IUPAC names are mentioned in Table 1.

\section{Protein preparation}

A molecular library of seven compounds (Ligand 1-7 along with reference compound) was docked with the five proteins for anticancer activity. Pdb files of all proteins viz. 2qc6, 1m17, 2pwb, 2v5z, 2v60, 2v61, 2ya3,4rui, 2f10, 3jsx were downloaded from PDB (www.rcsb. rg), having resolution of $2.20 \AA$ Å. Ramachandran plot of pdb files $(2 \mathrm{v} 5 \mathrm{z}, 2 \mathrm{v} 60$, $2 v 61$, and 2qc6) of proteins amine oxidase and protein kinase showing the best result with designed ligands are mentioned in Fig. 2.

\section{Grid generation}

The best interaction between one or more ligands and receptor molecules can be studied with Glide search. The receptor grid can be set up and generated from the receptor grid generation panel. Without generating receptor grid, ligand cannot be docked with receptors. In this study, OPLS_2005 force field was used for generating grid.

\section{Molecular docking}

Docking studies of ligands and proteins [24] were performed to determine anticancer activity $[25,26]$. The selected ligands and proteins were docked using Schrodinger software. The docking program evaluated energies to obtain the best binding mode. The docking score of all designed ligands, reference compound with proteins amine oxidase, NQ01, EGFR, protein P450, and protein kinase are mentioned in Table 2.

\section{Hydrogen bond interaction}

The amino acids of the protein interact with set of designed ligands and contribute the main role in their binding. The higher affinity of these

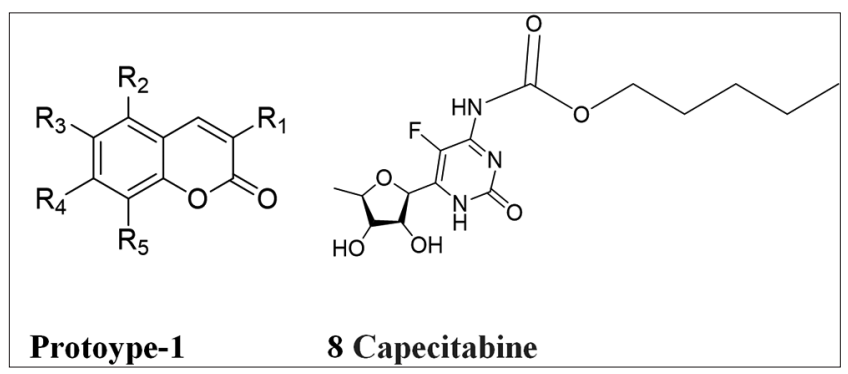

Fig. 1: Structure of prototype-1 of docked ligands and reference compound

Table 1: Substituentsof designed ligands with their IUPAC name

\begin{tabular}{|c|c|c|c|c|c|c|}
\hline Ligands & $R_{1}$ & $\mathbf{R}_{2}$ & $\mathbf{R}_{3}$ & $\mathbf{R}_{4}$ & $\mathbf{R}_{5}$ & IUPAC name \\
\hline 1 & $-\mathrm{H}$ & $-\mathrm{H}$ & $-\mathrm{H}$ & $-\mathrm{H}$ & $-\mathrm{H}$ & 2H-Chromene-2-one \\
\hline 2 & $-\mathrm{H}$ & $-\mathrm{OH}$ & $-\mathrm{H}$ & $-\mathrm{OH}$ & $-\mathrm{H}$ & 5,7-dihydroxy-2H-chromene-2-one \\
\hline 3 & $-\mathrm{C}_{6} \mathrm{H}_{5}$ & $-\mathrm{OH}$ & $-\mathrm{H}$ & $-\mathrm{OH}$ & $-\mathrm{H}$ & 5,7-dihydroxy-3-phenyl-2H-chromen-2-one \\
\hline 4 & $-\mathrm{C}_{6}^{0} \mathrm{H}_{5}$ & $-\mathrm{OH}$ & $-\mathrm{H}$ & $-\mathrm{OAc}$ & $-\mathrm{H}$ & 5.hydroxy-2-oxo-3-phenyl-2H-chromen-7-yl acetate \\
\hline 5 & $-\mathrm{C}_{6}^{6} \mathrm{H}_{5}^{5}$ & $-\mathrm{OAc}$ & $-\mathrm{H}$ & $-\mathrm{OAc}$ & $-\mathrm{H}$ & 2-oxo-3-phenyl-2H-chromen-5,7-diyl diacetate \\
\hline 6 & $-\mathrm{C}_{6}^{6} \mathrm{H}_{5}^{5}$ & $-\mathrm{OH}$ & $-\mathrm{I}$ & $-\mathrm{OH}$ & $-\mathrm{I}$ & 5,7-dihydroxy-6,8-diiodo-3-phenyl-2H-chromen-2-one \\
\hline 7 & $-\mathrm{C}_{6}^{0} \mathrm{H}_{5}^{3}$ & $-\mathrm{OH}$ & $-\mathrm{CF}_{3}$ & $-\mathrm{OAc}$ & $-\mathrm{CF}_{3}$ & 5-hydroxy-2-oxo-3-phenyl-6,8-bis (trifluoromethyl)-2H-chromen-7-yl acetate \\
\hline
\end{tabular}

Table 2: Docking scores of ligand 1-7 and reference compound with protein amine oxidase, NQ01, EGFR, protein P450 and protein kinase

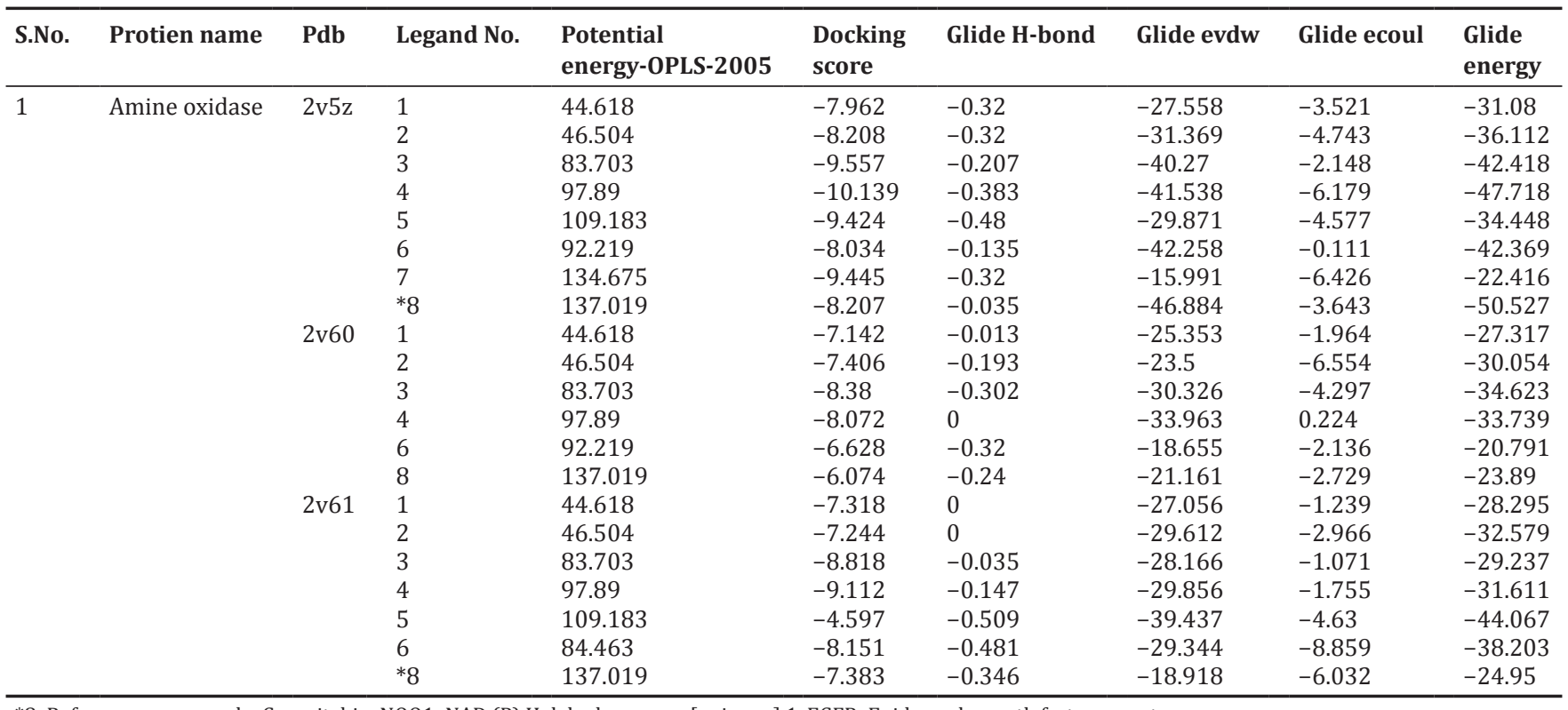

*8: Reference compound - Capecitabin. NQ01: NAD (P) H dehydrogenase [quinone] 1, EGFR: Epidermal growth factor receptor 
ligands to proteins was primarily due to the formation of hydrogen bonds. Number of hydrogen bonds provides stability to ligand-protein complex. Hydrogen bonding among amino acids of selected pdb files of proteins and ligand molecules, having docking score $<-8.00$ are given in Table 3.

\section{RESULTS AND DISCUSSION}

Docking simulation technique revealed very interesting results for library of designed ligands. Results indicated that binding of all designed ligands showed docking scores with 3 pdb files $2 \mathrm{v} 5 \mathrm{z}, 2 \mathrm{v} 60$, $2 \mathrm{v} 61$ of amine oxidase ranging from $(-7.962$ to -10.139$),(-7.142$ to $-8.38),(-4.597$ to -8.818$)$, and binding energies ranging from $(-22.416$ to -47.718$)$, ( -20.791 to -34.623$)$, ( -23.89 to -44.067$)$, respectively. Details of docking score and docking energies of ligands (1-7) and reference compound 8 with pdb files $2 v 5 z, 2 v 60,2 v 61$ of selected amine oxidase protein is mentioned in Table 2.

Graphical representation of docking score and docking energies of ligands 1-7 and reference compound 8 with pdb files of all selected proteins are well defined in Figs. $3 a$ and $b$.

These ligands were also analyzed for their potential energy-OPLS-2005, glide H-bond, glide evdw, and glide ecoul values. For all ligands OPLS-2005 values were ranging from -20.791 to -47.718 , values of glide $\mathrm{H}$-bond were found to be in the range of 0 to -0.481 , values of glide evdw were ranging from -15.991 to -46.884 , and values of glide ecoul were ranging from -0.111 to -8.859 . Standard values for glide evdw and ecoul should be $<100$ and glide H-bond it should be $<-0.05$ (Table 2).

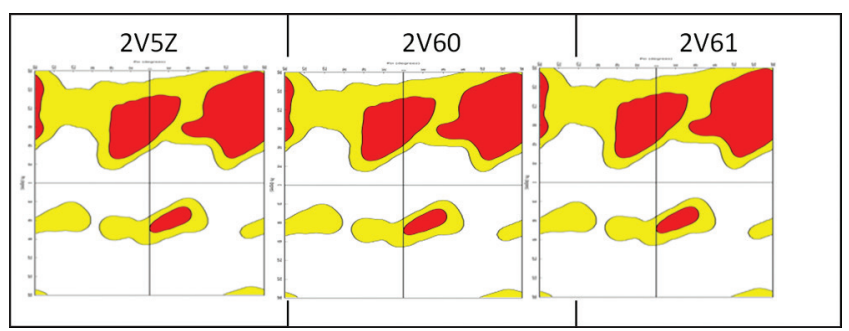

Fig. 2: Ramachandran plot of pdb files $(2 v 5 z, 2 v 60,2 v 61)$
These ligands were also studied for their hydrophobic interactions with selected pdb files having docking score $\leq-8.00$. It was analyzed that all seven ligand showed hydrophobic interactions with four pdb files $2 \mathrm{v} 5 \mathrm{z}, 2 \mathrm{v} 60$, and $2 \mathrm{v} 61$ in 11 different ways. The analysis of hydrophobic interactions of ligands $2,3,4,5,6,7$ with pdb file $2 \mathrm{v} 5 \mathrm{z}$ of protein amine oxidase are discussed herewith, namely, with ligand 2 residues were found to be Leu171, Tyr326, Phe343, Tyr60, Tyr435, Cys172, Ile198, Ile199, ligand 3 involved important hydrophobic/non-polar residues such as Phe168, Ile199, Leu171, Tyr326, Phe343, Leu328, Tyr60, Met341, Tyr435, Cys172, ligand 4 involved important hydrophobic/ non-polar residues such as Ile199, Ile316, Trp119, Phe168, Ile198, Cys172, Tyr188, Tyr398, Tyr435, Phe343, Tyr60, Leu328, Leu171, and $\pi-\pi$ interactions with Trp326, ligand 5 involved important hydrophobic/non-polar residues such as Ile198, Ile199, Ile316, Leu167, Leu168, Leu328, Leu171, Met341, Phe168, Phe343, Pro102, Pro104, Trp119, Tyr326, Tyr398, Tyr435, Tyr60, ligand 6 involved important hydrophobic/non-polar residues such as Cyr188, Cys172, Ile198, Ile199, Ile316, Leu164, Leu167, Leu328, Leu171, Phe168, Phe343, Pro102, Pro104, Tyr326, Trp119, Tyr398, Tyr435, Tyr60, and docked ligand 7 involved important hydrophobic/non-polar residues such Cys172, Ile198, Ile199, Ile316, Leu167, Leu328, Leu171, Phe168, Phe343, Tyr326, Trp119, Tyr398, Tyr435, Tyr60.

Similarly, ligand 3 and 4 showed hydrophobic interactions with pdb file $2 \mathrm{v} 60$ of amine oxidase. Wherein ligand 3 involved important hydrophobic/non-polar residues such as Ile316, Phe103, Leu164, Trp119, Phe168, Leu167, Cys172, Ile198, Tyr188, Tyr398, Tyr435, Phe343, Leu1171, Tyr326, Ile199, Phe99, Pro104 and ligand 4 involved important hydrophobic/non-polar residues such as Cys172, Ile198, Ile199, Ile316, Leu164, Leu167, Leu171, Met341, Phe168, Phe103, Pro102, Pro104, Phe343, Tyr60, Tyr398, Leu171 and $\pi-\pi$ interactions with Trp119, Tyr326.

Three ligands, i.e., 3, 4, 6were showing hydrophobic interactions with pdb file $2 \mathrm{v} 61$ of amine oxidase wherein ligand 3 involved important hydrophobic/non-polar residues such as Trp119, Pro104, Ile316, Pro102, Ile199, Leu328, Tyr60, Phe343, Tyr435, Ile198, Leu171, Cys172, Phe168, Leu167, Ile164, Trp119, and $\pi-\pi$ interactions with Tyr326, ligand 4 involved important hydrophobic/non-polar residues such as

Table 3: Receptor interactions within 4 Å for best ligands

\begin{tabular}{|c|c|c|c|c|c|}
\hline Protien & Pdb & H-Bonding & Hydrophobic residues & $\begin{array}{l}\text { Polar } \\
\text { residues }\end{array}$ & $\mathbf{P i}-\mathbf{P i}$ \\
\hline \multirow[t]{13}{*}{ Amine oxidase } & $2 v 5 z$ & & & & \\
\hline & 2 & & Tyr435, Tyr396, Tyr188, Tyr326, Phe343, Tyr60, Cys172, Ile198, Ile199 & Gln206 & - \\
\hline & 3 & & $\begin{array}{l}\text { Phe168, Ile199, Leu171, Tyr326, Phe343, Leu328, Tyr60, Met341, Tyr435, } \\
\text { Cys172, Ile198 }\end{array}$ & Gln206 & - \\
\hline & 4 & & $\begin{array}{l}\text { Ile199, Ile316, Trp119, Phe168, Ile198, Cys172, Tyr188, Tyr398, Tyr435, } \\
\text { Phe343, Tyr60, Leu328, Leu171 }\end{array}$ & $\mathrm{Gln} 206$ & Tyr326 \\
\hline & 5 & - & $\begin{array}{l}\text { Ile198, Ile199, Ile316, Leu167, Leu168, Leu328, Leu171, Met341, Phe168, } \\
\text { Phe343, Pro102, Pro104, Trp119, Tyr326, Tyr398, Tyr435, Tyr60 }\end{array}$ & Gln206 & \\
\hline & 6 & - & $\begin{array}{l}\text { Cyr188, Cys172, Ile198, Ile199, Ile316, Leu164, Leu167, Leu328, Leu171, } \\
\text { Phe168, Phe343, Pro102, Pro104, Tyr326, Trp119, Tyr398, Tyr435, Tyr60 }\end{array}$ & Gln206 & - \\
\hline & 7 & - & $\begin{array}{l}\text { Cys172, Ile198, Ile199, Ile316, Leu167, Leu328, Leu171, Phe168, Phe343, } \\
\text { Tyr326, Trp119, Tyr398, Tyr435, Tyr60 }\end{array}$ & Gln206 & - \\
\hline & $2 v 60$ & & & & \\
\hline & 4 & - & $\begin{array}{l}\text { Cys172, Ile198, Ile199, Ile316, Leu164, Leu167, Leu171, Met341, Phe168, } \\
\text { Phe103, Pro102, Pro104, Phe343, Tyr60, Tyr398 }\end{array}$ & Gln206 & Trp119, Tyr326 \\
\hline & $2 v 61$ & & & & \\
\hline & 3 & & $\begin{array}{l}\text { Trp119, Pro104, Ile316, Pro102, Ile199, Leu328, Tyr60, Phe343, Tyr435, } \\
\text { Ile198, Leu171, Cys172, Phe168, Leu167, Ile164, Trp119 }\end{array}$ & - & Tyr326 \\
\hline & 4 & - & $\begin{array}{l}\text { Cys172, Ile198, Ile199, Ile316, Leu164, Leu167, Leu328, Leu171, Phe103, } \\
\text { Phe168, Phe343, Pro102, Pro104, Tyr60,Tyr398 }\end{array}$ & $\mathrm{Gln} 206$ & Trp119, Tyr326 \\
\hline & 6 & & $\begin{array}{l}\text { Ile316, Pro104, Leu164, Trp119, Leu167, Phe168, Leu171, Tyr188, Ile198, } \\
\text { Cys172, Tyr435, Tyr398, Phe343, Tyr60, Leu328, Tyr326, Ile199, Pro102 }\end{array}$ & Gln206 & - \\
\hline
\end{tabular}


Cys172, Ile198, Ile199, Ile316, Leu164, Leu167, Leu328, Leu171, Phe103, Phe168, Phe343, Pro102, Pro104, Tyr60, Tyr398, and $\pi-\pi$ interactions with Trp119, Tyr326, and ligand 6 involved important hydrophobic/nonpolar residues such as Ile316, Pro104, Leu164, Trp119, Leu167, Phe168, Leu171, Tyr188, Ile198, Cys172, Tyr435, Tyr398, Phe343, Tyr60, Leu328, Tyr326, Ile199, Pro102 with no $\pi-\pi$ interactions.

All the docked ligands 1-7 involved important polar residues Gln206. Details of hydrophobic interactions of above-mentioned ligands are given in Table 3. 2D and 3D representation of all ligands showing hydrophobic interactions in pictorial form are mentioned in Figs. 4-15.

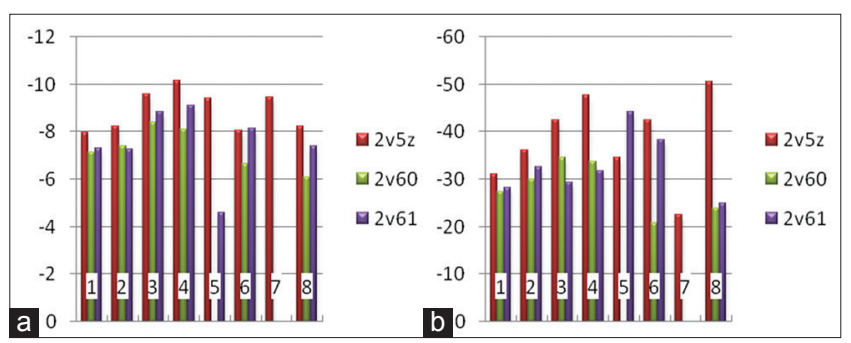

Fig. 3: ( $a$ and b) Docking score and docking energy of ligands

1-7 and reference compound 8 with pdb files $(2 v 5 z, 2 v 60,2 v 61)$ of protein amine oxidase

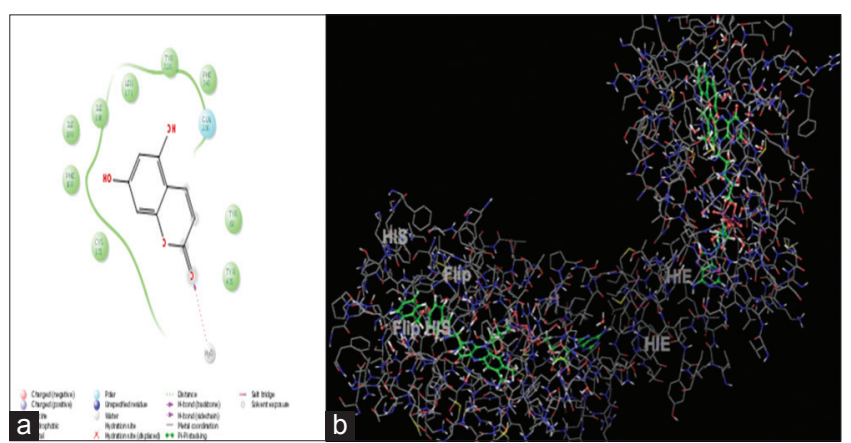

Fig. 4: Hydrophobic interaction of ligand 2 with $2 \mathrm{v} 5 \mathrm{z}$ two-dimension (a) and three-dimensional (b)

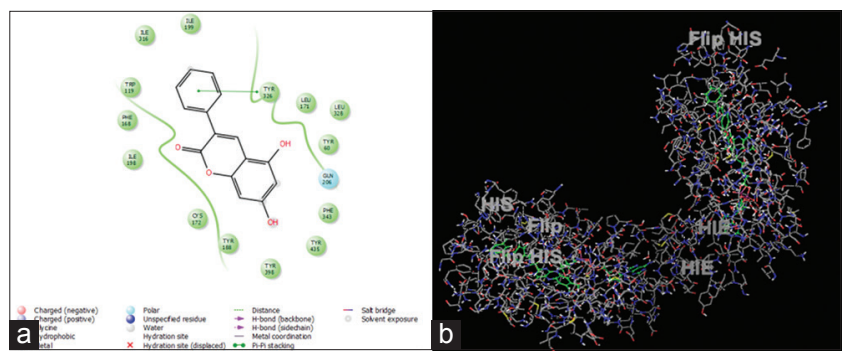

Fig. 5: Hydrophobic interaction of ligand 3 with $2 \mathrm{v5z}$ two-dimensional (a) and three-dimensional (b)

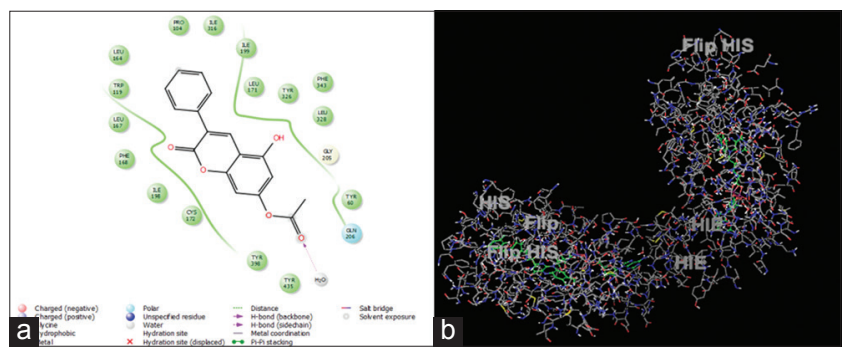

Fig. 6: Hydrophobic interaction of ligand 4 with $2 v 5 z$ two-dimensional (a) and three-dimensional (b)

\section{CONCLUSION}

The aim of the present study was to find out inhibitor ligands for 5 selected proteins, i.e., amine oxidase, NQ01, EGFR, P450, and protein kinase, which could interfere at molecular level to reduce expression of these proteins to control and prevent cancer. Docking studies were performed for unknown coumarin derivatives (ligands 3-7) and for coumarin congeners (ligands 1-2, possible precursors of ligands 1-7) for a better understanding of docking studies using Schrodinger software. Docking studies included calculation of docking score, docking energy, ecoul, H-bond, evdw and hydrophobic interaction of these ligand with selected proteins. Based on docking studies it was found that all ligands showed excellent binding with 3 pdb files $(2 \mathrm{v} 5 \mathrm{z}, 2 \mathrm{v} 60$ and $2 \mathrm{v} 61)$ of amine oxidase. They showed mild to moderate binding with all pdb files of proteins; averagely these ligands showed better binding than reference compound capecitabine.

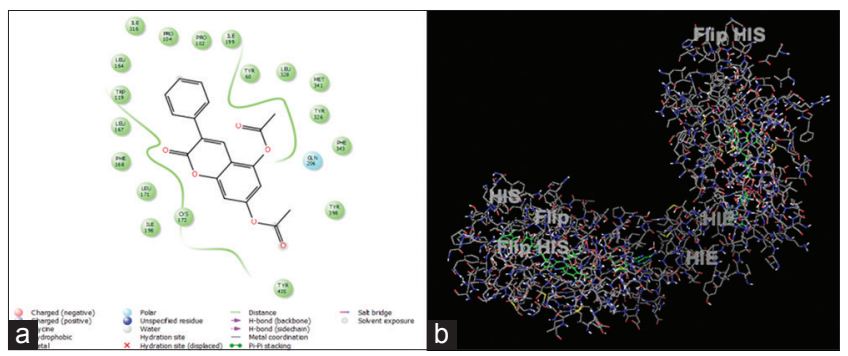

Fig. 7: Hydrophobic Interaction of ligand 5 with $2 \mathrm{v} 5 \mathrm{z}$ two-dimensional (a) and three-dimensional (b)

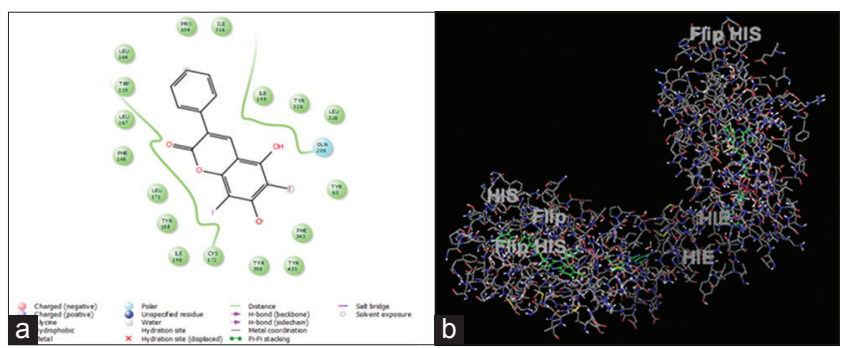

Fig. 8: Hydrophobic interaction of ligand 6 with $2 \mathrm{v} 5 \mathrm{z}$ two-dimensional (a) and three-dimensional (b)

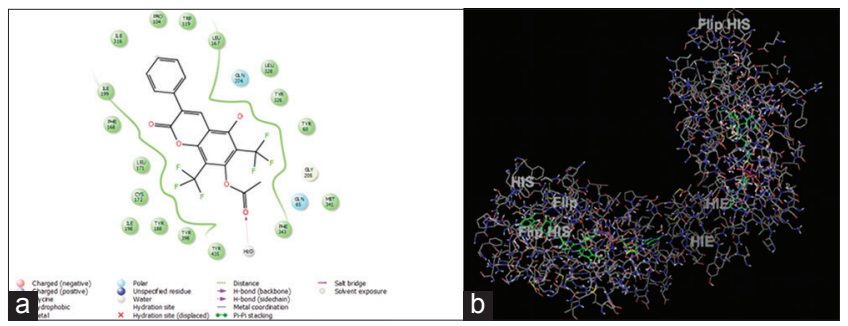

Fig. 9: Hydrophobic interaction of ligand 7 with $2 \mathrm{v} 5 \mathrm{z}$ two-dimensional (a) and three- dimensional (b)

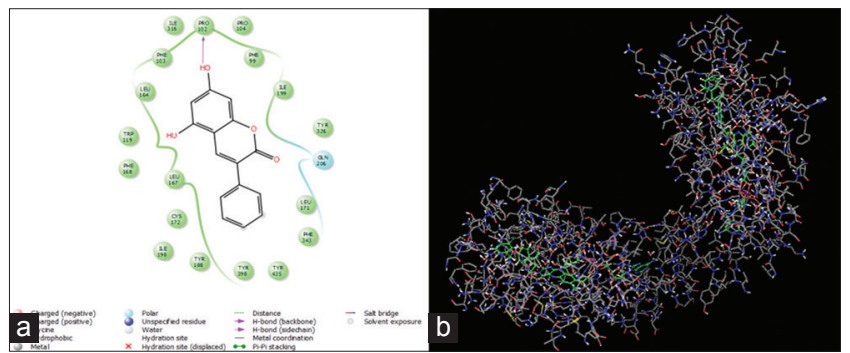

Fig. 10: Hydrophobic interaction of ligand 3 with 2v60 two-dimensional (a) and three- dimensional (b) 


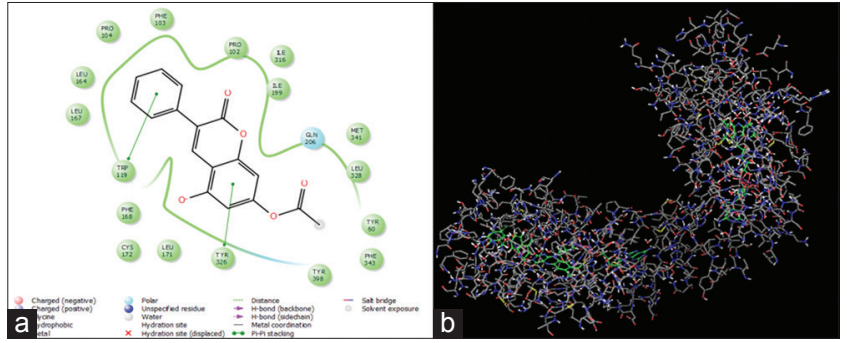

Fig. 11: Hydrophobic interaction of ligand 4 with $2 v 60$ two-dimensional (a) and three- dimensional (b)

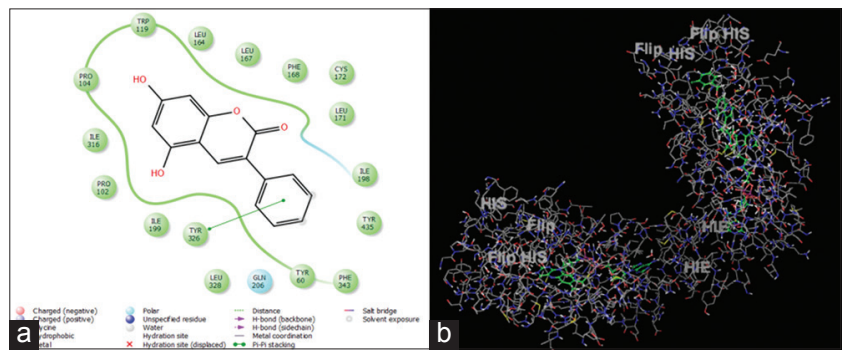

Fig. 12: Hydrophobic interaction of ligand 3 with $2 \mathrm{v} 61$ two-dimensional (a) and three- dimensional (b)

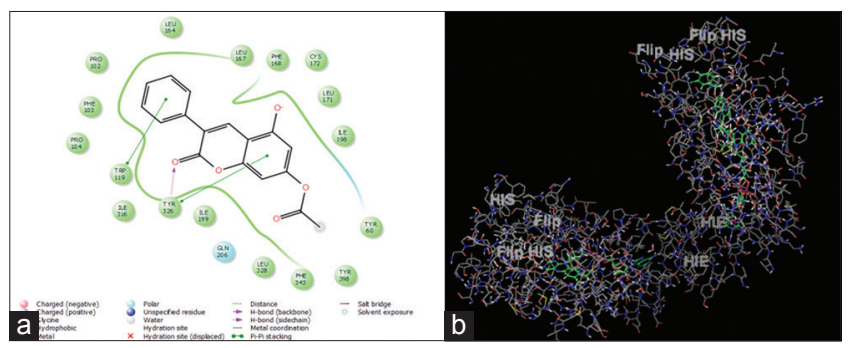

Fig. 13: Hydrophobic interaction of ligand 4 with 2v61 two-dimensional (a) and three- dimensional (b)

Upon visualization of results of docking studies in the form of Glide docking scores from the library of designed ligands (2-7), it was found ligands (2-7) showed docking scores (-8.034 to -10.139$)$ and docking energy ( -31.08 to -50.527$)$ for pdb files $2 \mathrm{v} 5 \mathrm{z}$ of amine oxidase. Similarly, for pdb $2 \mathrm{v} 60$ of amine oxidase ligands 3 and 4 showed docking scores $(-8.072$ and -8.38$)$, docking energies $(-33.739$ and -34.623$)$ respectively. Likewise for pdb file $2 \mathrm{v} 61$ of amine oxidase, ligands 3,4 and 6 showed docking scores $(-8.818,-9.112$ and -8.151$)$ and docking energies $(-29.237,-31.611$ and -38.203$)$ respectively. It can also be inferred that above-mentioned ligands showing docking score $<-8.00$ exhibited excellent hydrophobic interactions with proteins. They are also well in a range of six parameters for calculation of $\mathrm{G}$ score.

Therefore, we conclude that above mentioned 11 interactions of ligands (2-7) with three pdb files of protein amine oxidase and one pdb file of protein kinase are giving very exciting results, it was also found that ligand 4 was showing excellent docking score, i.e., $(-10)$ including all parameters of G score, with pdb file (2v5z) of amine oxidase. Hence, ligands (2-7), with a particular focus on ligand 4 can be developed as the excellent lead for a potential inhibitor of amine oxidase for their anticancerous activity. Authors wanted to generate these compounds as novel anticancerous drug, as coumarin derivatives are associated with antioxidant properties and with minimum side effects. Further wet laboratory studies are continued in our laboratory to confirm the properties of these ligands molecules.

\section{ACKNOWLEDGMENT}

The authors are thankful to the Amity University, Gurgaon, India, for providing Schrodinger Software Maestro facility for computational studies to carry out research work.

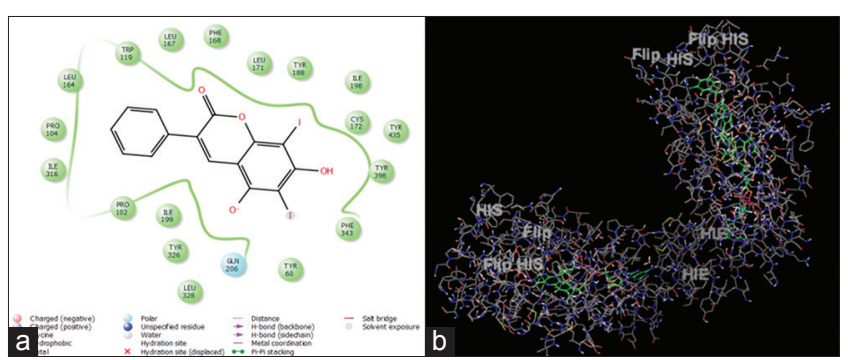

Fig. 14: Hydrophobic interaction of ligand 6 with $2 \mathrm{v} 61$ two-dimensional (a) and three- dimensional (b)

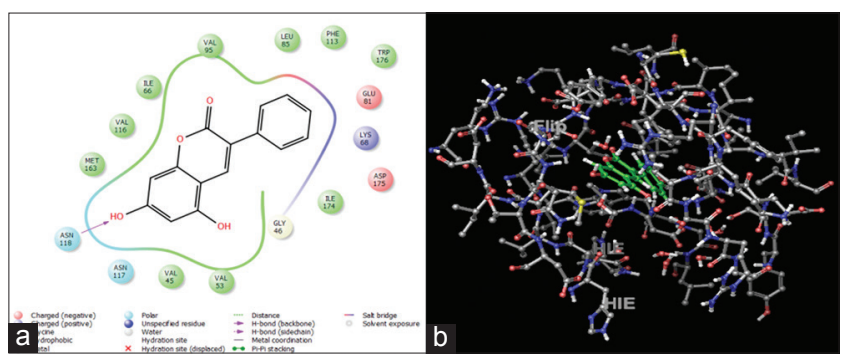

Fig. 15: Hydrophobic interaction of ligand 3 with 2 qc6 two-dimensional (a) and three-dimesnional (b)

\section{REFERENCES}

1. Gupta M, Dahiya J, Marwaha RK, Dureja H. Therapies in cancer treatment: An overview. Int J Pharm Pharm Sci 2015;7(4):1-9.

2. Sloane D. Cancer epidemiology in the United States: Racial, social, and economic factors. Methods Mol Biol 2009;471:65-83.

3. Klenkar J, Molnar M. Natural and synthetic coumarins as potential anticancer agents. J Chem Pharm Res 2015;7(7):1223-38.

4. Ostrov DA, Hernández Prada JA, Corsino PE, Finton KA, Le N, Rowe TC. Discovery of novel DNA gyrase inhibitors by high-throughput virtual screening. Antimicrob Agents Chemother 2007;51(10):3688-98.

5. Kostova I. Coumarins as inhibitors of HIV reverse transcriptase. Curr HIV Res 2006;4(3):347-63.

6. Shih JC, Chen K, Ridd MJ. Monoamine oxidase: From genes to behavior. Annu Rev Neurosci 1999;22:197-217.

7. True L, Coleman I, Hawley S, Huang CY, Gifford D, Coleman R, et al. A molecular correlate to the Gleason grading system for prostate adenocarcinoma. Proc Natl Acad Sci U S A 2006;103(29):10991-6.

8. Ishar MP, Singh G, Singh S, Sreenivasan KK, Singh G. Design, synthesis, and evaluation of novel 6-chloro-/fluorochromone derivatives as potential topoisomerase inhibitor anticancer agents. Bioorg Med Chem Lett 2006;16:1366-70.

9. Nioi P, Hayes JD. Contribution of $\mathrm{NAD}(\mathrm{P}) \mathrm{H}$ : Quinone oxidoreductase 1 to protection against carcinogenesis, and regulation of its gene by the Nrf2 basic-region leucine zipper and the arylhydrocarbon receptor. Mutat Res 2004;555(1-2):149-71.

10. Nolan KA, Doncaster JR, Dunstan MS, Scott KA, Frenkel AD, Siegel $\mathrm{D}$, et al. Synthesis and biological evaluation of coumarin-based inhibitors of NAD(P)H: Quinone oxidoreductase-1 (NQO1). J Med Chem 2009;52:7142-56.

11. Normanno N, De Luca A, Bianco C, Strizzi L, Mancino M, Maiello MR, et al. Epidermal growth factor receptor (EGFR) signaling in cancer. Eur J Cancer 2006;366(1):2-16.

12. Normanno N, De Luca A, Bianco C, Strizzi L, Mancino M, Maiello MR, et al. Epidermal growth factor receptor (EGFR) signaling in cancer. Gene 2006;366(1):2-16.

13. Patil RB, Sawant SD, Reddy KV, Shirsat M. Synthesis, docking studies and evaluation of antioxidant activity of some chromenone derivatives. Res J Pharm Biol Chem Sci 2015;6(2):381-91.

14. Caro AA, CederbaumAI. Oxidative stress, toxicology, and pharmacology of CYP2E1. Annu Rev Pharmacol Toxicol 2004;44:27-42.

15. Oyama T, Sugio K, Isse T, Matsumoto A, Nose N, Uramoto H, et al. Expression of cytochrome P450 in non-small cell lung cancer. Front Biosci 2008;13:5787-93.

16. Rodriguez-Antona C, Ingelman-Sundberg M. Cytochrome P450 pharmacogenetics and cancer. Oncogene 2006;25(11):1679-91.

17. Yano JK, Hsu MH, Griffin KJ, Stout CD, Johnson EF. Structures of 
human microsomal cytochrome P450 2A6 complexed with coumarin and methoxsalen. Nat Struct Mol Biol 2005;12(9):822-3.

18. Yano JK, Hsu MH, Griffin KJ, Stout CD, Johnson EF. Structures of human microsomal cytochrome P450 2A6 complexed with coumarin and methoxsalen. Nat Struct Mol Biol 2005;12(9):822-3.

19. Patents: Furo-coumarinsulfonamides as Protein Kinase C Inhibitors. Available from: http://www.google.com/patents/US5216014.

20. Marshall ME, Butler K, Hermansen D. Structural modification of coumarin for increased anti-coagulation potency. Prostate 1990; $17: 95-108$

21. Sashidhara KV, Kumar A, Kumar M, Sarkar J, Sinha S. Synthesis and in vitro evaluation of novel coumarin-chalcone hybrids as potential anticancer agents. Bioorg Med Chem Lett 2010;20(24):7205-11.

22. Ganugapati J, Swarna S. Molecular docking studies of antidiabetic activity of cinnamon compounds. Asian J Pharm Clin Res 2014;7(2):1-4.
23. Fadilah F, Arsianti A, Kusumardi K, Tedjo A. Molecular docking studies of analogues of antimycin $\mathrm{A}_{3}$ as caspases inhibitors of apoptosis in colorectal cancer. Asian J Pharm Clin Res 2016;9(3):350-2.

24. Tiwary BK, Pathak RK, Pradhan K, Nanda AK, Bothra AK, Chakraborty R. Evaluation of drug candidature of some quinazoline4-(3h)-ones as inhibitor of human dihydrofolatereductase enzyme: Molecular docking and in silico studies. Int J Pharm Pharm Sci 2014;6(2):393-400.

25. Gupta P, Rai N, Gautam P. Anticancer drugs as potential inhibitors of acrab-tolc of multidrug resistant Escherichla coli: As in silico molecular modeling and docking study. Asian J Pharm Clin Res 2015;8(1):351-8.

26. Sabitha K, Kodous A, Rajkumar T. Computational analysis of mutations in really interesting new gene finger domain and BRCA1 C terminus domain of breast cancer susceptibility gene. Asian J Pharm Clin Res 2016;9(3):96-102. 